\title{
Implementation of Techniques and its Management on Constructional Activities
}

\author{
Madan Kumar L., Vadiraj Rao N.R., Chandana Prasad B.G., Rajani A.
}

\begin{abstract}
Precast construction is a time effective technique which consumes less time than cast-in-situ technique for execution. Savings of time in construction would compensate the overall profit for the owner. Precast technology achieves better concrete quality control with less wastage of materials. In this paper, $G+3$ commercial multi-storied building is planned and compared with the precast construction and cast-in-situ construction for cost analysis using Payback Period Method and Net Present Value Method. Scheduling is done using Primavera. Primavera (P6) turn out to be competent tool in monitoring, scheduling, controlling and updating the project at any stage of construction process. Through payback period it is able to deduce that, the initial investment can be recovered approximately one month before the cast-in-situ method when we are employing precast approach. Also, considering investment criteria i.e. Net present value method shows that, a higher profit is obtained towards the investment in precast than in cast-in-situ method. Hence, precast construction method proves to be profitable when compared to conventional method of construction.
\end{abstract}

Index Terms-Cast-in-situ, Net Present Value Method, Payback Period Method, Precast, Primavera.

\section{INTRODUCTION}

The construction industry has been progressing rapidly with the introduction of latest systems of construction and technologies. One of the most time effective and quality monitored systems i.e., precast concrete technique, is widely adopted by many countries around the globe. India is an infrastructure famished country. Precast construction is a well known technique in which standardized units are manufactured in manufacturing plants and are used for swift construction. Despite the technology being developed years ago, its implementation is limited in India. With the progress in technology, the construction industry evolves at a faster rate which in turn provides a broad spectrum for the introduction of precast concrete construction technique. Currently, fast track building construction is a rapidly developing technique, and saving of time in construction would compensate the overall construction cost, making precast technology widely accepted all over India. Precast concrete is a construction product produced by casting concrete in a reusable mould or form which is then cured in a controlled environment, transported to the construction site and lifted into place. Project monitoring and control is the process of collecting, recording, and reporting data concerning project performance. Project controlling uses the

Revised Manuscript Received on July 18, 2019.

Madan Kumar L., Department of Civil Engineering, The National Institute of Engineering, Mysuru, India.

Vadiraj Rao N.R., Department of Civil Engineering, The National Institute of Engineering, Mysuru, India. National Institute of Engineering, Mysuru, India.

Rajani A., Department of Civil Engineering, The National Institute of Engineering, Mysuru, India.
Chandana Prasad B.G., Department of Civil Engineering, The

information from monitor activity to bring actual performance to planned performance [1].

Akash and Venkateswarlu [2] investigated various precast methods and designs. From the results it is observed that, the design turns out to be economical if proper care has been taken while designing the structure.

Further, the same building is designed by both traditional and precast technique and from the results it is observed that the cost and duration of construction of precast building is significantly less than traditional method. Capital budgeting [3] is a decisive feature for the organization's triumph for various reasons. First, capital investments ordinarily account for a huge amount of funds of the firm. Second, once an investment decision has been taken, capital investments usually have a groundlaying effect on the future cash flows of the firm. Third, once the funds have been pledged, it is seldom possible to reverse it, nor it is affordable to do so as funds are normally tied up for a considerable period of time. Ultimately, investments influence the profitability and longstanding policy of the firm. The following techniques are used: The Net Present Value (NPV), the Payback Period (PB), Accounting Rate of Return (ARR), Internal Rate of Return (IRR), Profitability Index.

Shaikh et al. [4] has discussed about the project monitoring process and has compared the planned progress and actual progress of the construction work of the Standard design Factory, a four storey factory building project at Cochin Kerala, Total Contract Value of 7 crores, built-up area 5472 sqm, and expected time to complete within 21 months. The progress at site is incorporated in Primavera (P6) scheduled and updated. The result obtained is, the project is behind the actual schedule, the project progress is $51.73 \%$ at $62.48 \%$ of consuming total estimated project duration. Schedule Variance (SV) is $-11.05 \%$ therefore project is $11.05 \%$ behind the schedule. The project was delayed by 2.6 months. This investigation proved to be a guideline in understanding the progress of standard design factory construction work and also to identify the progress of the construction work. Primavera (P6) proves to be an efficient tool in monitoring, scheduling, controlling and updating the project at any stage of construction process to meet the project requirements. Prajwal et al. [5] arrived at the conclusion that, the use precast technique is almost doubled in the past 15 years, increasing by $86 \%$. Sesmic resistant structures can be built with little investment and less time. The utilization of prefabricated materials obviously decreases the waste created in the sites and environmental hazards are also reduced. The labors number 
can be decreased and their safety can also be assured. Bindurani et al. [6] carried out a case study on a 23- storied building, of precast wall panels and slabs, to study the modeling of vertical joints in terms of shear transfer, which consists of two computational models. It was perceived that the model, which is not making allowances for shear transfer through the vertical joints, prone to yield conservative results in terms of amount of steel requirement.

From the case study conducted by Hong Kong construction industry [7], it was observed that the cost of construction is moderately higher than conventional construction when adopting precast technique. Yet, this is balanced by improved quality, reduction in construction time, and refined on-site environmental performances. Based on previous research papers and articles the present study of comparing time and cost parameters between Castin-situ construction and precast technique construction has been made.

\section{METHODOLOGY \& TEST RESULTS}

A (G+3) multi-storied commercial building has been taken as case study for the present investigation. Then comparison has been made between Cast-in-situ type of construction and precast tech- nique construction by considering cost and time parameters.

\section{A. Comparative Study Of Cast-In-Situ And Precast Type Of Construction}

In the present study, analysis of time and cost parameter has been examined and compared between both Cast-in-situ and Precast technique type of construction. Using Primavera software sched- uling for both the methods has been done and for determination of cost parameter Microsoft Excel was used.

In cast-in-situ, construction of all the building elements are casted at site such as beams, columns, slabs etc. In precast construction precast element i.e., beams, columns and slabs are manufactured in precast factory and transported to site for installation.

\section{a.Time Analysis}

By using Primavera software scheduling of the project is done. Total duration of the project for Cast-in-situ method is 13 months (Fig.1 - Fig. 6). Total duration of the project for Precast construc- tion is 9.5 months (Fig. 7 - Fig. 10).

\section{Scheduling of Cast-in-situ method of Construction:}

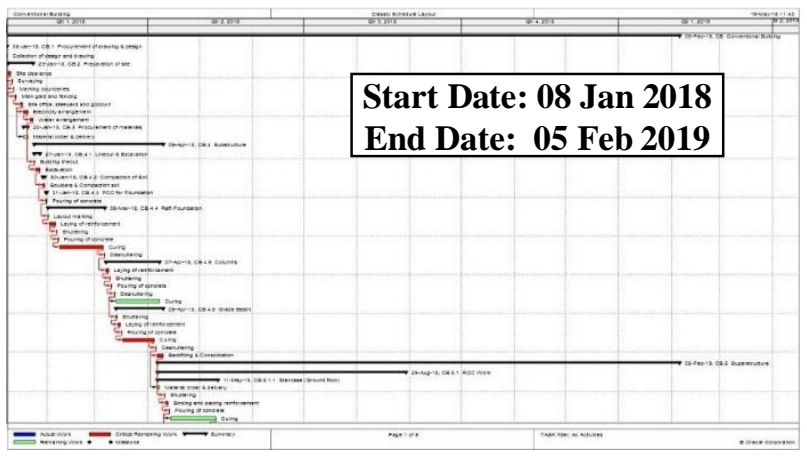

Fig 1: Scheduling of Conventional method of construction from 08-Jan-18 to May-18

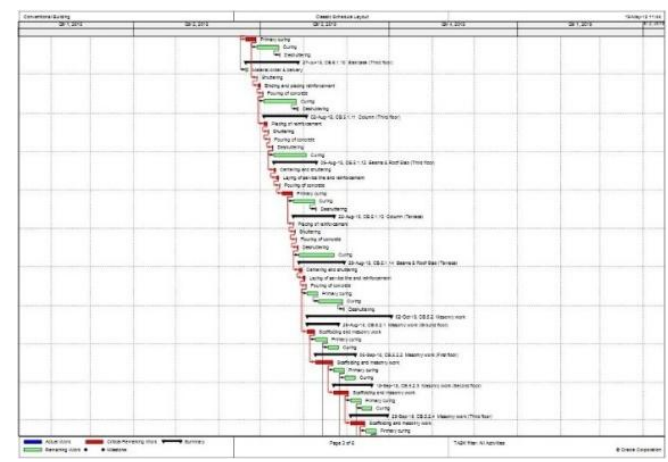

Fig. 2 Scheduling of Conventional method of construction from May-18 to July-18

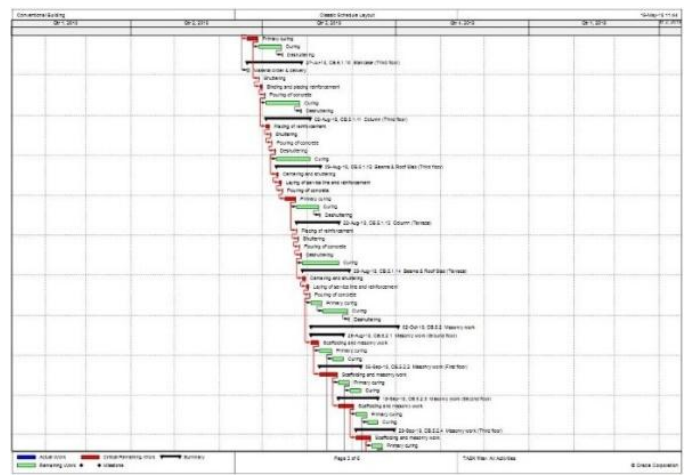

Fig. 3 Scheduling of Conventional method of construction from July-18 to Sep-18

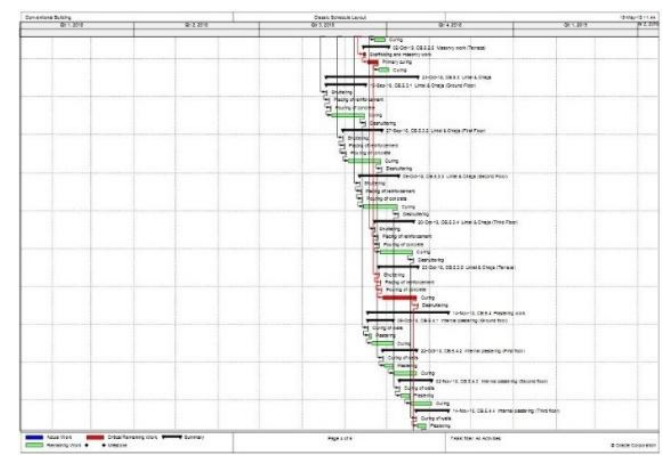

Fig. 4 Scheduling of Conventional method of construction from Sep-18 to Nov-18

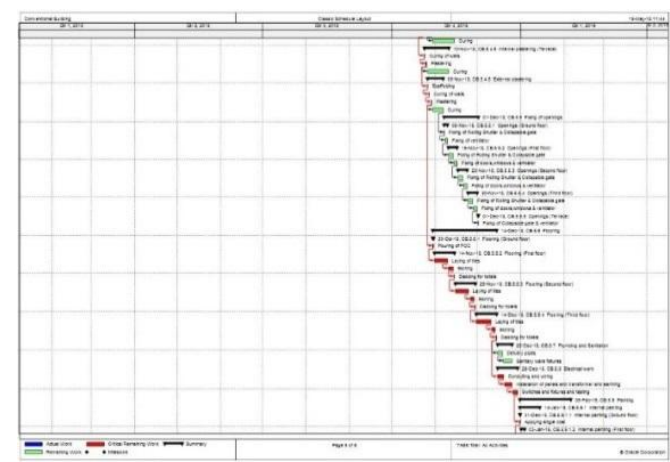

Fig. 5 Scheduling of Conventional method of construction from Nov-18 to Jan-19 


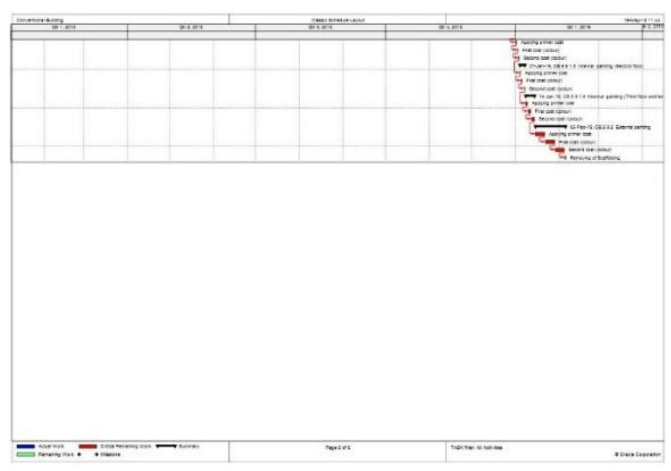

Fig. 6 Scheduling of Conventional method of construction from Jan-19 to 05-Feb-19.

Scheduling of Precast Construction:

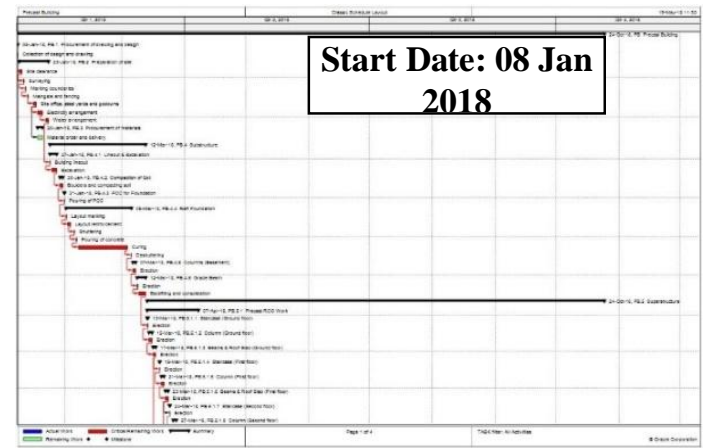

Fig.7 Scheduling of Precast Construction from 08-Jan-18 to Mar-18.

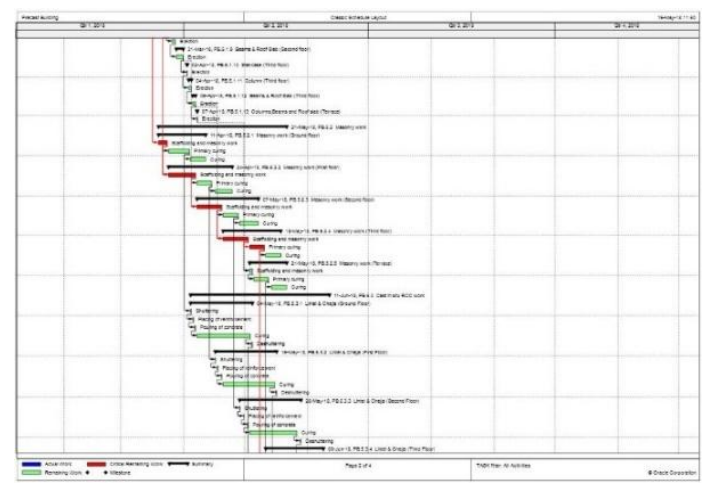

Fig. 8 Scheduling of Precast Construction from Mar-18 to Jun-18

Fig. 9 Scheduling of Precast Construction from Jun-18 to Sep-18.

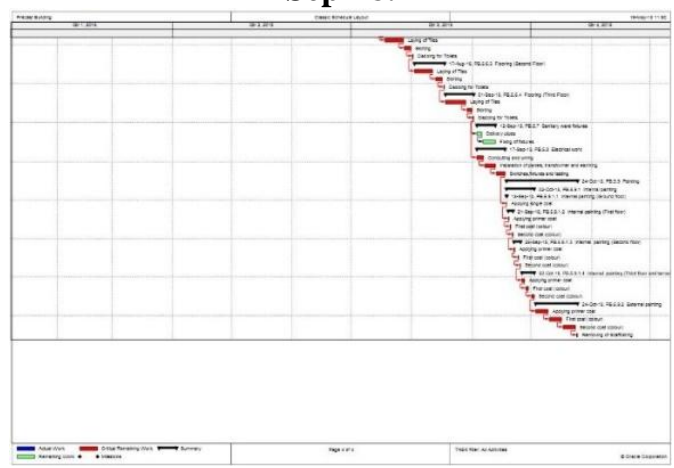

Fig.10 Scheduling of Precast Construction from Sep-18 to 24-Oct-18.

\section{b. Cost Analysis}

Cost of precast construction technique may differ with the size and type of construction. For smaller projects, the cost of precast increases due to manufacturing of less number of units where high investment that has been made for moulds. For bigger project, cost may decrease significantly.

Total cost for cast-in-situ construction is "One hundred and eight Lakhs and twenty thousand rupees only".

Total cost of precast construction is "One hundred and fourteen lakhs and ninety-five thousand rupees only".

By using Payback period method:

By collecting filed data of rents, annual cash inflow was deter- mined. For, 1st floor, 2nd floor and 3rd floor rent of Rs. 80 /-, Rs. 70 /- and Rs. 50 /- per sq. ft. was fixed respectively.

Total area in sq. $\mathrm{ft}$. of each floor $=1628.99 \mathrm{ft}$.

1st floor: Rent = Rs. 1628.99 x $80=$ Rs. $1,30,319.248 /-$

2nd floor: Rent = Rs. 1628.99 x 70= Rs. $1,14,029.342 /-$. 3rd floor: Rent = Rs. 1628.99 x 50= Rs. 81,449.53/-

Therefore, total rent or cash inflow for every month $=$ Rs. $3,25,798.12 /-$.

Hence, annual cash inflow $=(12 \times 3,25,798.12)=$ Rs.39,09,577.44

Rs. 39,00,000.00 /-.

Payback period for Cast-in-situ method $=10820000 /$ $3900000=$

2.77 years $\sim 33.29$ months (Fig. 11).

Payback period for Precast method $=11495000 / 3900000$ $=2.94$ years $\sim 35.37$ months.

As precast construction gives us a heads up on cash inflow for 3 months, let's deduct those months in the payback period method. Therefore, payback period of precast $=35.37-3=32.37$ months $($ Fig. 11)

Hence from the above method we can compare the results and the amount of time required to regain the money invested is less in precast and it is more preferable when compared to cast-in-situ method.

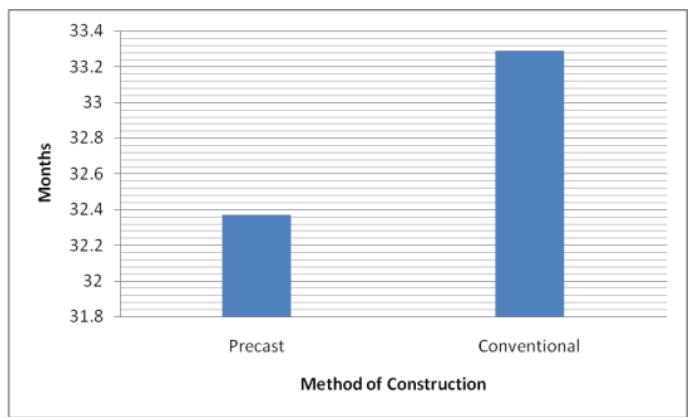

Fig. 11: Payback period for Cast-in-situ and Precast technique type of construction

By using Net Present Value (NPV) method:

$$
N P V=\sum_{t=1}^{T} \frac{C_{t}}{(1+r)^{t}}-C_{0}
$$

$\mathrm{Ct}=$ net cash inflow during the period $\mathrm{t}$

$\mathrm{Co}=$ total initial investment costs 
$r=$ required rate of return

$\mathrm{t}=$ number of time periods

Cast-in-situ method:

Initial investment $=108.20$ lakhs Annual Cash inflow $=39$ lakhs

Assuming 10 percent increment in the rent every year Required rate of return $=10$ percent

Assuming number of time periods for 5 years NPV= Rs. 69,06,658 /- (Fig. 12).

Precast method:

Initial investment= 114.95 lakhs Annual Cash inflow $=39$ lakhs

Assuming 10 percent increment in the rent every year Required rate of return $=10$ percent

Assuming number of time periods for 5 years NPV= Rs. $62,62,272 /$-.

As precast construction gives us a heads up on cash inflow for 3 months, the rent for the respective months should be added to NPV of precast in order to justify and compare both of them.

Therefore: $62,62,272+(3,25,798.12 \times 3)=$ Rs.

72,39,666/- (Fig. 12).

Hence according to Net present value method precast has highest positive value than the cast-in-situ method and it is most suitable investment criteria.

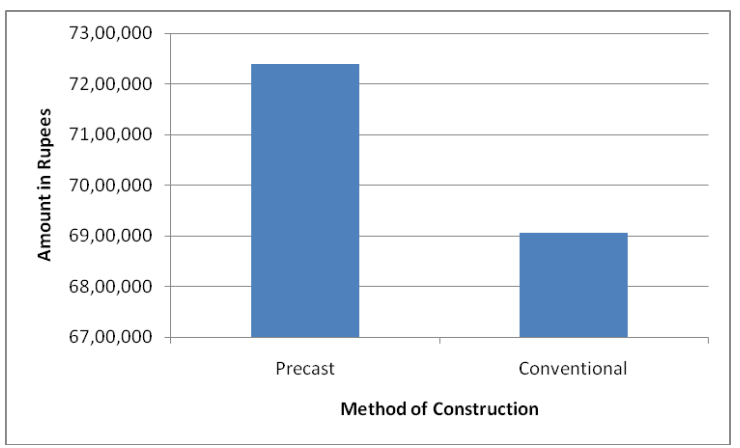

Fig. 12 Net Present Value for Cast-in-situ and Precast type of construction.

\section{CONCLUSIONS}

After a detailed study of plan, estimation, scheduling and also management studies like investment criteria, the following conclusions have been made:

As time is one of the greatest essentialities, scheduling shows the brief description that when we consider precast type of construction method, it gives a head start of 3 months with a masonry wall included in it.

$>$ Time scheduling and critical paths of both methods can be seen through the primavera which is one of the efficient project management software.

$>$ Through payback period it is able to deduce that the initial in- vestment can be recovered approximately 1 month before the cast- in-situ method when we are employing precast approach.

$>$ Also, considering an investment criterion i.e., Net present value method, it shows that a more positive attitude is obtained towards the investment in precast than in cast-in-situ method.
Precast construction method proves to be profitable when com- pared to conventional method of construction.

\section{ACKNOWLEDGEMENT}

Authors are thankful to Department of Civil Engineering, NIE, Mysuru and KEF infrastructure Pvt. Ltd. India, for encouraging and extending the facilities and inputs for the project.

\section{REFERENCES}

1. F.T. Andrew and P. Sachin, "Project Monitoring and Control using Primavera - Project Planning Monitoring \& Control", International Journal of Innovative Science Engineering and Technology, Vol. 2, No. 3, (2013), pp.762-771.

2. L. Akash, and D. Venkateswarlu, "Design, Cost \& Time analysis of Precast \& RCC building”, International Research Journal of Engi- neering and Technology, Vol.03, No. 06, (2016), pp. 343-350.

3. Vongai Maroyi, Capital Budgeting Practices: A South African Per- spective, Master's Thesis, Wageningen University, Department of Social Sciences, Management Studies Group, (2011).

4. A. A. Shaikh, K.J. Geetha and R. Ramya, "Time and Cost Analysis under Project Planner Software", Department of Civil Engineering, Shivajirao S. Jondhle College of Engineering and Technology, Asangaon, (2013).

5. P. Prajjwal, D. Sagar, B. Madan, T. Amit Kumar Tomar, "Study on Prefabricated Modular and Steel Structures", SSRG International Journal of Civil Engineering, Vol.3, No. 5, (2016), pp. 7-14

6. P. Bindurani, A. Meher Prasad, A. K. Senugupta, "Analysis of Pre- cast Multi store Building - A Case Study", International Journal of Innovative Research in Science, Engineering and Technology Vol. 2, No. 1, (2013), pp.294-302.

7. L. Jaillon and C.S. Poon, "Advantages and Limitations of Precast Concrete Construction in High-rise Buildings: Hong Kong Case Study", CIB World Building Congress, (2007), pp. 2504-2514.

8. IS 456: 2000, Indian Standard plain and reinforced concretecode of practice (4th revision), April 2007.

9. SP: 16- 1980, Design Aids for Reinforced Concrete to IS: 456-1978, Mar 1999.

10. SP: 34(S\&T)- 1987, Hand Book on Concrete Reinforcement and Detailing, Mar 1999

11. IS: $875-1978$, part 1 and part 2, Code of practice for Design Load.

12. Unnikrishna Pillai and Devdas Menon, Reinforced Concrete Design, 3rd Edition, Mcgraw Hill Publication.

13. N. Krishna Raju, Reinforced Concrete Design, 2nd Edition, CBS Publications.

14. H.J. Shah, Reinforced Concrete Vol-1 and Vol-2, 8th Edition, 2009 and 6th, Edition 2012, Charotar Publication

\section{AUTHORS PROFILE}

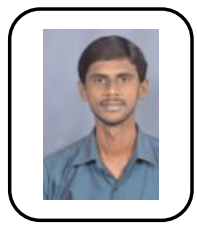

Mr Madan Kumar L completed his B.E from S.J.M Institute of Engineering, Chitradurga. Afterwards, he did his M.Tech in Construction Technology from B.M.S College of Engineering, Bengaluru. He has one international journal, one international

conference
$\&$

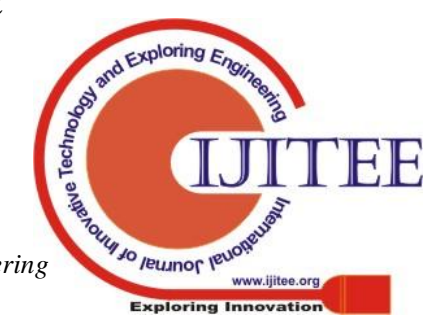


one national conference. Currently, he is a member for managing committee for Association of Consulting Civil Engineers (India), Mysuru Centre. His research work mainly includes construction management, concrete and highway materials.

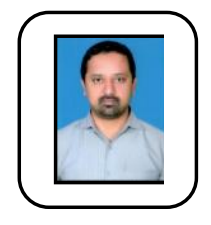

Mr. VADIRAJ RAO N R had completed his B.E \& M. Tech from Visveswaraiah Technological University (VTU), Belgaum. He had worked as a structural engineer in various consultancy firms including L\&T constructions. His areas of interest include structural engineering, design of RC structures and project management. Presently he is working as assistant professor in the department of civil engineering, NIE, Mysore.

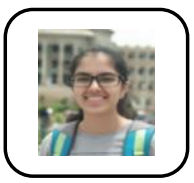

Ms. CHANDANA PRASAD B.G. currently pursuing her B.E in civil engineering. Her area of interest includes construction management.

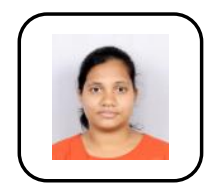

Ms. RAJANI A. currently pursuing her B.E in civil engineering. Her area of interest includes construction management. 